Portland State University

PDXScholar

$11-18-2018$

\title{
A Literature Review on Body-Worn Cameras for Law Enforcement
}

Steven Witt

Portland State University

Follow this and additional works at: https://pdxscholar.library.pdx.edu/honorstheses Let us know how access to this document benefits you.

\section{Recommended Citation}

Witt, Steven, "A Literature Review on Body-Worn Cameras for Law Enforcement" (2018). University Honors Theses. Paper 660.

https://doi.org/10.15760/honors.675

This Thesis is brought to you for free and open access. It has been accepted for inclusion in University Honors Theses by an authorized administrator of PDXScholar. Please contact us if we can make this document more accessible: pdxscholar@pdx.edu. 
A Literature Review of Body-Worn Cameras for Law Enforcement

\author{
by \\ Steven Witt
}

An undergraduate honors thesis submitted in partial fulfillment of the requirements for the degree of

Bachelor of Arts

in

University Honors

and

Criminology \& Criminal Justice

\author{
Thesis Adviser \\ Aaron Roussell
}




\begin{abstract}
:
Officer body-worn cameras, or BWCs, are an evolving technology impacting policing. The technology is quickly being implemented by police departments across the United States to increase transparency in police-public interactions and also to provide a more accurate account of what happened in a given incident. This technology has been of particular interest in the wake of high profile lethal force incidents in the United States; multiple studies over the time period of 2014-2018 have examined whether BWCs can reduce use of force incidents by law enforcement officers. Research conducted on BWCs in the United States present mixed findings: BWCs demonstrate the ability to lower both use of force incident rates and complaints against law enforcement officers, and also have significant monetary costs and privacy risks, especially if improperly implemented. The significant costs, benefits, and risks associated with the technology account for why BWCs will always be a controversial issue and why the technology will always have its supporters and critics.
\end{abstract}




\section{Introduction:}

There has been an extensive amount of research done on the topic of Body Worn Cameras, or BWCs, over the past several years, starting in 2014. BWCs are video capturing devices placed either on an officer's shoulder, chest, or head. The footage it takes may not always be clear or particularly useful, but nonetheless is a potential tool for increasing police accountability and transparency. Before 2014, there had been no major studies done in the United States on the topic of BWCs. After the first large scale study in Rialto, California, researchers began studying a variety of topics related to BWCs. This paper is a literature review of these studies, along with other types of research done on the topic of BWCs, along with examining the specific costs, benefits, risks, and ethics of BWCs.

The sources used for this paper can roughly be divided into several categories. First, there are the large-scale studies, like the one done in Rialto, testing for specific variables using Randomized Control Trials (RTC) to assess the impact BWCs have on variables such officer use of force, complaints against officers, policing tactics, etc. The second type of material is comprehensive reports by prominent organizations, which are typically longer documents that summarize all of the available information on BWCs to date, explaining the research done on the topic and current policies related to BWCs. It should be noted that unlike all other sources used in this paper, comprehensive reports are not primary research but rather summarizing research that has already been done, as does this paper. The last type of research is various articles written about BWCs, usually about more specific issues than large scale studies or comprehensive reports.

This paper is organized categorically, citing the relevant research for each BWC topic in each section. The large-scale studies discussing research done on how the cameras affect policing are addressed in the first part of the paper. The comprehensive reports will appear throughout the 
paper, as they touch on all areas regarding the technology. The various articles written on BWCs tend to relate to BWC policies, privacy concerns, and risks. Those will appear mostly in the second half of the paper.

The paper begins by discussing the results of large scale studies done on BWCs, measuring variables such as whether BWCs have an impact on variables such as officer use of force, rates of complaints against officers, and how BWCs affect policing tactics. The paper then discusses the monetary costs and privacy concerns of BWCs. After that, policy implications and organizations affecting those decisions will be discussed. The paper will end with discussing both officer and public perceptions of BWCs, along with explaining why the technology will always have its supporters and critics.

Throughout the paper there will be reference to reasons why people support or do not support the use of this technology. By understanding the research, we will be in the best position to make choices regarding whether and how to implement BWC Technology and be able to craft policies to make the technology a useful and reliable tool. 


\section{Studying how BWCs Impact Policing:}

Before 2014, there were no large-scale studies done in the United States on Body-Worn Cameras, or BWCs. There had been some smaller scale studies done in the United Kingdom and surrounding areas between 2006 and 2010 which indicated that BWCs had some potential reduce use of force incidents by officers, though the results were inconclusive. Researchers in the United States decided to conduct their own studies on BWCs, beginning with in Rialto California. The Rialto study was a catalyst for many other studies of BWC technology.

In 2014 the results of the first large scale study of the impact of officer body worn cameras, or BWCs have on policing was published. This study, in Rialto California, found that BWCs reduced complaints against Rialto officers by approximately $90 \%$ and reductions in the use of force by officers by approximately $50 \%$. The study was done over the course of 12 months analyzing 988 shifts of a total 54 officers, 489 shifts with BWCs and 499 without (Ariel, Farrar, $\&$ Sutherland, 2014). This is promising research of the efficacy of BWCs to foster a better relationship between law enforcement and the rest of society, but further testing was surely needed to corroborate the positive benefits.

There are several studies that tested similar research questions to the Rialto study, such as whether a body-camera worn during a police interaction would reduce the likelihood of the officer using force and whether a body-camera would reduce the number of complaints against officers. It is clear why these questions were the primary questions of research for these large scale studies: Many initiatives to have BWCs implemented have been a result of people trying to fix broken police-community relations, such as a 2013 court order that the New York Police Department implement BWCs after their stop and frisk policy was declared unconstitutional (White, 2014). Similarly, the Orlando Police Department conducted a study after community 
members requested BWCs after a series of officer involved shootings (Sousa, Coldren, Rodriguez, \& Braga, 2016).

The research design in Rialto was a randomized controlled trial and subsequent studies have also continued using this method. In a randomized control trial, one group of subjects are randomly assigned to a "treatment"- that is, exposed to an intervention-while a second group - the control group — is not. Due to the random assignment, differences between the two groups are evidence an effect caused by treatment. Studies conducted compared officers using BWCs to other officers not using BWCs over the same period of time, as opposed to equipping everyone with BWCs and comparing those results to previous data.

Examples of experimental studies modeled on the Rialto study include the two Arizona studies done in Mesa and Phoenix in 2013 (Katz, Choate, Ready, \& Nuňo, 2014; White, 2014), a study on the Orlando Police department in 2015 (Jennings, Lynch, \& Fridell, 2015), a study on the Las Vegas Police Departments (Braga, Coldren, Sousa, Rodriguez, \& Alper, 2017), the Tampa, Florida study (Braga et al., 2017), and a study done again in Rialto several years after the original study to see if the same positive benefits from BWCs remained (Ariel, 2017).

All of these studies found that BWCs impacted policing tactics, some with significant reductions in use of force and complaints against officers. In Mesa AZ, officers not wearing BWCs conducted more stop and frisks and made more arrests, while citizen complaints against those wearing cameras went down 36\% (Ready \& Young, 2015). In Orlando and Las Vegas there were reductions in use of force among officers wearing BWCs, down $53 \%$ in Orlando and $14 \%$ in Las Vegas. Tampa found an $8 \%$ reduction in use of force with officers using BWCs, and fewer arrests and more citations made among those using the BWC. Whether the increase in citations is a good or bad thing is a topic open for discussion, as it's possible that citations are 
being made in place of arrest, or whether the citations are being made because officers feel they have less discretion to excuse an offense that can be cited.

Along with citing differences in officer use of force and complaints against officers, one study in 2017 by the same group that conducted the Rialto study went back to Rialto to see if the same positive benefits remained after the implementation period. The results confirmed that the reductions in use of force and complaints were reduced even after the study period of the BWCs, indicating that it was the cameras, rather than the study period, that lead to the positive results. ( Ariel, Sutherland, Farrar, \& De Anda, 2017)

There was one significant anomaly in the literature of studying how BWCs impacted police use of force/ complaints against officers. A multi-site experiment conducted in 2016 by the same group that conducted the Rialto study found no change in officer use of force, and found that BWCs increased assaults against police officers. The reason this anomaly is significant is that it used more hours of footage over more departments for the study than had ever been done before for a BWC study, analyzing thousands of shifts from 10 different cities. This obfuscates the overall picture, and what the literature says in regards to whether BWCs reduce officer use of force; most of the smaller studies found reductions, while one large study found no reduction. ( Ariel, et al. 2017 )

Another question researchers were interested in is whether officers would engage more or less with the public with BWC camera rolling. Every single study that asked the question of whether officers engaged more or less with the public as a result of wearing the camera came to the same conclusion: wearing BWCs make officers more likely to engage with the public, and in these interactions, officers were more likely to give citations, rather than making arrests (Kotowski, 2016). This matches well with officers' perceptions regarding the impact of BWCs on their 
work, as $84 \%$ of officers responded on a survey that they did not feel that BWCs would reduce their likelihood of responding to calls for service (Cubitt, Lesic, Meyers, \& Corry, 2016). Conversely, researchers found that officers not wearing body cameras were more likely to conduct a stop and search and make an arrest (White, 2014).

\section{Monetary Costs}

It costs money to implement and maintain body cameras, and more money to store and effectively analyze the data. Several sources estimate the average cost of implementing a camera for one officer to be around $\$ 1,000$, not including fees associated with maintenance or data storage (Kotowski, 2016; White, 2014). This initial implementation cost is not the bulk of the monetary costs; in the long term it will be more expensive to support the infrastructure of BWCs, which is primarily the archiving of massive amount of footage that will need to be properly managed.

Kotowski (2016) argues that storage is the primary cost. Larger departments can generate up to 10,000 hours of BWC footage per week; the New Orleans Police department estimated the implementation and maintenance of such technology would cost $\$ 1.2$ million (Kotowski, 2016). Many argue that these steep monetary costs are what society must pay for accountability and transparency of police procedure.

Despite the massive financial costs, there seems to be some monetary benefits from BWCs that can more than justify the investment. The Rialto study demonstrated fewer complaints against police officers, which resulted in fewer payouts as a result of officer misconduct. Researchers/Rialto PD estimated that the BWCs saved them four times as much money as it cost to implement the cameras (Ariel, Farrar, \& Sutherland, 2014; White, 2014) 


\section{Privacy Concerns:}

There are serious privacy concerns that must be taken into account when implementing cameras worn by police that will be continuously recording the public and adding the information to data archive without any safeguards as to the usage of that data or how long it will be kept. There are reasonable concerns for everyone surveilled by the cameras: those directly involved with law enforcement, law enforcement themselves, suspects, victims, witnesses, etc.

Privacy concerns related to BWCs is a serious issue, and often a primary reason for those opposing usage of the technology. There are multiple aspects to this, such as the way BWC evidence can be used to convict people. The possibility of BWCs capturing footage of people in a vulnerable situation, such as after being the victim of a crime, also presents a significant privacy concern that needs to be taken into account when creating policy.

BWCs are different from other footage capturing devices, such as dashcams. A frame of reference for video footage captured on foot during policing is footage shown on the television show COPS, where there is often a camera person following an officer around, not involved in the actual conflict, focusing their attention on recording the incident with their professional grade cameras. It's very unlikely to always have such clear footage result from incidents where officers are wearing smaller cameras that present only one angle of what happened. The officers are not concerned with producing a clear picture of what happened on camera, but rather are engaged primarily in handling the incident at hand. Since the footage is a second concern, it may be an unclear record of the event.

These specific limitations are demonstrated in an article by the New York Times (Williams, Jacoby, \& Cave, 2016). The article displayed BWC footage from the officer's angle during an 
altercation with a lot of movement, where it seemed that the person the officer was interacting with was acting an aggressive manner, potentially necessitating the use of force. However, when viewed from another angle, it was clear that there was no threat to the officer. One example is where it looks from the first angle like the officer is being assaulted, but it turns out that from the other angle the two are dancing together.

In the second example, a cop pursues someone on foot and takes them down, then yells into the camera that the person he chased down is reaching for his weapon. From another angle, it is clear that the only reason the person's arms are flailing are because they are being tazed, and are clearly not a danger to the cop (Williams, Thomas, Jacoby, \& Cave, 2016). These are examples of how an incomplete narrative can be formed on the basis of only BWC camera footage, and how a small camera in chaotic motion can often have a difficult time showing what actually happened. There are reasonable concerns for the public to have based on these demonstrations, and the laws regarding convictions based on BWC footage should take into account the limitations of the technology. Similar concerns regarding equal access to the footage by officers and suspects are taken up below in the section on policy guidelines for BWCs.

The cameras capture more than just suspects of a crime and the officers involved in the incident; they capture everything within their view. Another article points out that while cameras are often implemented with the idea of monitoring officer behavior, "cameras point outward, recording the community and its residents, all of whom are beyond the intended subject" (Adams $\&$ Mastracci, 2017). The article talks in detail about the risks of BWCs, arguing that the technology of BWCs are evolving faster than the laws concerning privacy are, and that cameras can violate victim's dignity and privacy, and potentially "revictimize victims of sexual and domestic violence." This will be discussed further in the section on policy guidelines, as there 
are decisions to be made about when police officers are allowed to have the discretion to not record an incident, particularly in the case of a victim asking for an event not to be recorded.

There are certainly BWC videos released to the public depicting events that people on the cameras would rather not have released. There is no one set rule across departments for what footage can and can't be released; departmental policy varies regarding when releasing footage is acceptable. From looking through available footage, it seems unlikely that in high profile cases with available BWC footage will be kept from the public. For example, the deadly incident at Northern Arizona University where Steven Jones shot multiple students was a high-profile case with a lot of attention, as there was significant controversy as to whether his actions qualified as self-defense. While those specifics are outside the scope of this paper, the fact that BWC footage was released showing Steven Jones hysterical as officers arrived on the scene, crying that he wanted his mother, seems to indicate that there is little reason to believe that BWC footage with significant public interest will be kept private. However, if departments choose to, it is likely they will be able to keep much of BWC footage under lock and key.

Law enforcement can also have reasonable concerns for their privacy, given that officers constantly interact with the public in uncomfortable situations. BWCs make their responses to every situation potentially visible to their supervisors. While accountability is important and a key feature of using such technology, researchers understand that "there are concerns that officers may be subjected to unsolicited fishing expeditions by supervisors," and officers could potentially be less inclined to initiate with the public if "they feel micromanaged in an era of digital surveillance" (White, 2014). 


\section{Body-worn Camera Policies:}

The usage and implementation of BWCs requires planning and clear policy; failing to do so could both negate any positive benefits associated with the technology, and also violate the privacy and dignity of those surveilled. The first comprehensive report published in 2014 talked of several organizations detailing policies for BWC usage, with some differences between the two. These two organizations are the American Civil Liberties Union (ACLU), and Police Executive Research Forum (PERF).

These two organizations lay out, in a slightly different manner, the policies they recommend for BWCs. The differences in how they are written is that the ACLU is more specific in its recommendations, while the PERF is more general in their recommendations. The ACLU makes a list of exactly the circumstances in which a BWC should be rolling, among other policy decisions, while the PERF makes fewer specific recommendations, and more often details how different departments handle things, without a definite decision on which is the best. The policy topics these organizations cover are questions such as when to record, notification of recording, recording inside the home, and data storage policies.

The most discussed policy question in both the ACLU Article (Stanley, 2013) and the PERF Article (Miller, Tolliver, 2014) is when the cameras should be recording. The two organizations largely agree that except in very specific circumstances, the cameras should be rolling when an officer is on duty. Both organizations mention specific exceptions to recording, such as recording at a time that would be insensitive to a victim, such as a rape case, or when someone is willing to give police testimony only if the cameras are off. 
The next policy topic is about notifying people that they are being recorded. The ACLU argues for explicitly notifying people being surveilled, stating "Officers should be required, wherever practicable, to notify people that they are being recorded (similar to existing law for dash cams in some states). One possibility departments might consider is for officers to wear an easily visible pin or sticker saying "lapel camera in operation" or words to that effect." (Ramirez 2014,pg.16)

The PERF, not specifically choosing which policy it endorse, states that different departments handle the issue differently, depending on whether the state is a one or two party consent state for recording laws. In two party consent states, officers are required to notify of recording, while in one party consent states officers are always required to, but often encouraged. As is consistent with the rest of the policy recommendations from the two organizations, this represents how the ACLU is for slightly stricter BWC policy for law enforcement officers, while the PERF argues for slightly more flexibility in law enforcement decision making in regards to the technology.

The two agencies also seem to differ on how they view recordings inside a home taken by a BWC, and the admissibility of what the camera captures as evidence. The PERF states what multiple agencies do, rather than detailing a specific policy: "Many law enforcement agencies have taken the position that officers have the right to record inside a private home as long as they have a legal right to be there." (Miller, Toliver, 2014, pg15).

This is further clarified by a statement from a Deputy Chief of Police quoted in the same article stating " Here in Albuquerque, everything is open to public record unless it is part of an ongoing investigation. So if police come into your house and it is captured on video, and if the video isn't 
being used in an investigation, your neighbor can request the footage under the open records act, and we must give it to them." (Miller, Toliver, 2014, pg 15).

The ACLU responded, stating "An officer might be allowed to go into the residence and record, but that does not mean that everything inside ought to be public record. The warrant is an exception to the Fourth Amendment, not a waiver." (Miller, Toliver 2014, pg 15). It's clear from this exchange that the PERF sees BWCs as an extension of already used surveillance technology, such as the fact that surveillance inside people's homes taken from a TV crew ends up on the show COPS regularly, and the ACLU is more concerned about the release of information taken inside the home.

The last topic to be discussed for policy recommendations is retention and storage of data taken by BWCs. The PERF states that for non-evidentiary video footage, or footage not being used in any case, the most common time period for it to be stored is 60 to 90 days, with the longest time being a year for one department. Evidentiary video, or those being used in an ongoing case, are subject to state evidentiary laws, which vary. The PERF does not make a recommendation, it just explains how different departments have fairly similar policies on this issue. The ACLU is more explicit: "Retention periods should be measured in weeks, not years, and video should be deleted after that period unless a recording has been flagged. Once a recording has been flagged, it would then switch to a longer retention schedule (need to follow state requirements)" (Ramirez, 2014).

It's clear that the two organizations discussed have slightly different views on how BWC technology should be used, though there is a fair amount of overlap. Generally, the PERF has a looser policy guideline where it describes how several different departments handle things, while the ACLU is advocating for stricter policies and codes of conduct. It is difficult to determine the 
extent to which each of these organizations has influenced current BWC policy with their recommendations.

\section{Perceptions of Body-worn Cameras:}

Research has been conducted into how officers perceive police BWCs sometimes before, during, and after implementation. Both the police and public have mixed perceptions of BWCs. Surveys of how officers perceive BWCs are done frequently in conjunction with experimental studies on the efficacy of BWCs to improve the relationship between law enforcement and those they police in categories such as reductions in complaints and reductions in use of force. There are fewer studies done on public perceptions of BWCs. The term "perceptions" covers areas such as whether or not people believe the technology is effective at providing a better account of what happened in an interaction, to whether people act better on cameras, to whether BWCs are worth the costs.

One article discussed how officers perceive BWCs before they are implemented, and how these perceptions change after working with the technology.[ Title gone ] (Gaub, Choate, Todak, Katz, \& White, 2016) The different departments studied were in Phoenix, AZ, Tempe, AZ, and Spokane, WA. Of the three departments, officers in Tempe and Spokane had increases in positive attitudes toward the technology after working with it. Officers' view in Phoenix views started negative and remained so - the officers did not buy into the technology, despite documented reductions in complaints against Phoenix officers who wore cameras. The researchers suggested that this could be a historical effect: because this was the first study of the three done, at that time BWCs were a novel technology that officers generally viewed with suspicion. 
Officers that have input into the process of BWC implementation within a given department are more likely to comply with policy, and there are more likely to be positive benefits derived from the technology. BWC researcher Michael White states "It is just as important to be transparent with officers as it is with the community" (White, 2014). Rialto's police department was an example of this, and perhaps one of the reasons BWC implementation was so successful there. In addition participation in policy implementation, police departments with longer training periods of BWC implementation are more likely to have officers perceive the technology positively.

Citizen perceptions of BWCs have been studied considerably less often, although one study analyzed 81 interviews with people of different backgrounds to understand their perspectives on BWCs. (Ray, Marsh, \& Powelson, 2017). The study asked numerous questions related to perceptions of BWCs. Ray and their colleagues found that minorities were slightly more likely than white people to support the use of BWC technology. For those skeptical of camera implementation, they categorized the skepticisms into two different categories: structural skeptics, who believed that problems in the criminal justice system would not be overcome by implementing BWCs, and privacy skeptics, who believed that the privacy risks were not worth whatever perceived benefits were to come from the cameras.

A research article published in 2018 featured examples of structural skeptics of BWCs. The article displays transcripts of conversations between researchers and citizens in Baltimore after the death of Freddie Gray. Participants were questioned about whether they believed that BWCs could help in areas such in officer accountability, and participants were generally skeptical that cameras would cause such improvements. (Kerrison, Cobbina \& Bender, 2018) 
These are perfect examples of structural skeptics, those who believe that the current problems in policing will not be improved by camera technology.

Overall, perceptions of BWCs from law enforcement and non- law enforcement are mixed, for a variety of reasons.

\section{Conclusion}

While the increasing amount of research done on BWCs over last 6 years has provided more insight into how the cameras impact policing, there is still no consensus on the technology. Proponents of BWCs will point to instances where police complaints and use of force go down, and departments save money by reductions in complaints, while skeptics of the technology will cite a large-scale study that found no difference in use of force by officers wearing BWCs, large financial costs, and numerous privacy concerns associated with surveillance technology.

The departments currently implementing BWC technology in their departments have more research to draw on now, guidelines as recommended by the ACLU and PERF, along with the numerous studies conducted all across the United States.

While there is still more work to be done in regards to studying every aspect of BWC technology, the research that has been conducted to this point has clearly demonstrated the possible costs, risks, and benefits of this technology. BWCs will be more ubiquitous in the United States in the coming years, changing modern policing to be more transparent. 


\section{References}

Adams, I., \& Mastracci, S. (2017). Visibility is a trap: The ethics of police body-worn cameras and control. Administrative Theory \& Praxis 39, 4, 313-328.

Ariel, B. Sutherland, A., Farar, W., \& De Anda, R. (2017). Post-experimental follow ups—Fadeout versus persistence effects: The Rialto policy body-worn camera experiment four years on. Journal of Criminal Justice 53, 110-116.

Ariel, B., Farrar, W., \& Sutherland, A. (2014). The effect of police ody-worn cameras on use of force and citizens' complaints against the police: A randomized controlled trial. Journal of Quantitative Criminology 31, 3, 509-535.

Braga, A., Coldren, J., Sousa, W., Rodriguez, D., \& Alper, O. (2017). The benefits of body-worn cameras: New findings from a randomized controlled trial at the Las Vegas Metropolitan Police Department. Police Quarterly 19, 3, 363-384.

Cubitt, T., Lesic, R., Meyers, G., \& Corry, R. (2016). Body-worn video: A systematic review of literature. Australian \& New Zealand Journal of Criminology 50, 3, 379-396.

Gaub, J., Choate, D., Todak, N., Katz, C., \& White, M. (2016). Officer perceptions of body-worn cameras before and after deployment. Police Quarterly 19, 3, 275-302.

Kerrison, E., Cobina,J., \& Bender, K. (2018). Stop-gaps, lip service, and the perceived futility of body-worn police officer cameras in Baltimore City. Journal of Ethnic \& Cultural Diversity in Social Work 27,3, 271-288. 
Jennings, W., Lynch, M., \& Fridell, L. (2015). Evaluating the impact of police officer body-worn cameras (BWCs) on response-to-resistance and serious external complaints: Evidence from the Orlando Police Department (OPD) experience utilizing a randomized controlled experiment. Journal of Criminal Justice 43, 6, 480-486.

Katz, C., Choate, D., Ready, J., \& Nuňo, L. (2014). Evaluating the Impact of Officer Worn Body Cameras in the Phoenix Police Department. Phoenix, AZ: Center for Violence Prevention \& Community Safety, Arizona State University.

Kotowski, J. (2016, March 8). Money, storage primary obstacles in police body camera implementation. Emergency Management. Retrieved from: www.govtech.com/em/safety/Police-Body-Cam-Installation.html

Miller, L., Tolliver, J, \& Police Executive Research Forum. (2014). Implementing a body-worn camera program: Recommendations and lessons learned. Washington, DC: Office of Community Oriented Policing Services. Ramirez, E. P. (2014). A report on body worn cameras. Los Angeles: Manning \& Kass, Ellrod, Ramirez, Trester LLP.

Ray, R., Marsh, K., \& Powelson, C. (2017). Can cameras stop the killings? Racial differences in perceptions of the effectiveness of body-worn cameras in police encounters. Sociology Forum 32, S1, 1032-1050.

Ready, J.T., \& Young J. T. N. (2015). The impact of on-officer video cameras on police-citizen contacts: Findings from a controlled experiment in Mesa, AZ. Journal of Experimental Criminology 11, 3, 445-458

Stanley, J. (2015, March). Police Body-Mounted Cameras: With Right Policies in Place, 
A Win for All (version 2.0). New York: American Civil Liberties Union. Retrieved from https://www.aclu.org/policebody-mounted-cameras-right-policies-place-win-all

White, M. (2014). Police officer body-worn cameras: Assessing the evidence. Washington, DC: Office of Community Oriented Policing Services, US Department of Justice.

Williams, T., Thomas, J., Jacoby, S., \& Cave, D. (2016, April 1). Police body cameras: What do you see? New York Times. Retrieved from https://www.nytimes.com/interactive/2016/04/01/us/police-bodycam-video.html 